\section{Side effects during continuous epidural infusion of morphine and fentanyl}

Martin J. White MB FCAnaes, Edward J. Berghausen MD, Stephen W. Dumont MB FFarCs, Kentaro Tsueda MD, Julia A. Schroeder MD, Robert L. Vogel PhD, Michael F. Heine MD, Kou Chu Huang MD
Respiratory effects, nausea, somnolence, and pruritus were compared during a 48-hr period of continuous epidural morphine $(n=34)$ and fentanyl $(n=32)$ infusion in 66 patients following elective total replacement of the hip or knee joint. Respiratory effects were assessed by $\mathrm{PaCO}_{2}$. Side effects were assessed by visual analogue scale and considered to be present when the score was above 30. Assessment was made at preoperative visits then $3,6,12,24,36$, and $48 \mathrm{hr}$ after the epidural injection. The bolus dose and subsequent infusion rate were 3,900 $\pm 1,300 \mu \mathrm{g}$ and $427 \pm 213 \mu \mathrm{g} \cdot \mathrm{hr}^{-1}$ for morphine, and $85 \pm 46 \mu \mathrm{g}$ and $56 \pm 27 \mu \mathrm{g} \cdot \mathrm{hr}^{-1}$ for fentanyl. Pain relief was similar in both groups. In the morphine group, $\mathrm{PaCO}_{2}$ elevation and nausea occurred over a period of more than 12 hr $(P<0.05)$. In the fentanyl group, there was no $\mathrm{PaCO}_{2}$ change, and nausea was confined to the first few hours. Nausea was more severe $(P<0.01$ at six hours and more frequent (24 hr cumulative incidence, 53 vs $28 \%, P<0.05$ ) in the morphine group. Somnolence was prominent within several hours in two-thirds of patients in both groups. Somnolence continued to decline thereafter in the morphine group, but it was demonstrable in approximately half of the patients throughout the second day in the fentanyl group. The incidence was higher in the fentanyl group at the 48th $\mathrm{hr}(P<0.05)$. There was a quadratic increase in pruritus over time $(P<0.001)$, and it was more severe in the morphine group $(P<0.001)$. Pruritus was generalized in the morphine group; but it was segmental in the fentanyl group. It remained the side effect of most clinical concern during the second day in both groups. The temporal course of respiratory effect and nausea

\section{Key words}

ANALGESIA: epidural, postoperative;

ANALGESICS: fentanyl, morphine;

COMPLICATIONS: pruritus, respiratory failure, somnolence.

From the Departments of Anesthesiology and Orthopedic

Surgery, University of Louisville, Louisville, Kentucky

Address correspondence to: Dr. Kentaro Tsueda, Depart-

ment of Anesthesiology, University of Louisville, Louisville, KY 40292.

Accepted for publication 29th March, 1992. were similar to that which follows a bolus epidural injection. Side effects were less during the second day of infusion in both groups with the notable exception of pruritus. Side effects were generally less in the fentanyl group. The continuous epidural infusion of opioids, after the initial bolus-related side effects, appears to be a safe technique for prolonged and steady pain relief with minimal side effects.

Soixante-six patients subissant un remplacement total de hanche ou de genou participent à cette étude. Les effets respiratoires, les nausées, la somnolence et le prurit associées à une perfusion épidurale continue de morphine ( $n=34)$ ou de fentanyl $(n=32)$ sont évalués durant les 48 heures qui suivent la chirurgie. Les effets respiratoires sont évalués par la mesure de la $\mathrm{PaCO}_{2}$. Une échelle analogue visuelle sert à évaluér la sévérité des nausées, le niveau de somnolence et l'intensité du prurit. Un pointage supérieur à 30 est nécessaire pour marquer la présence de ces symptômes. L'évaluation est faite lors de la visite préopératoire, puis $3,6,12,24,36$, et 48 heures après l'injection épidurale. La dose initiale et la vitesse de perfusion sont $3900 \pm 1300 \mu \mathrm{g}$ et $427 \pm 213 \mu \mathrm{g} \cdot h^{-1}$ pour la morphine, et $85 \pm 46 \mu \mathrm{g}$ et $56 \pm 27$ $\mu \mathrm{g} \cdot h^{-1}$ pour le fentanyl. L'analgésie postopératoire est comparable entre les deux groupes de traitement. Dans le groupe morphine, les nausées et les élévations de la $\mathrm{PaCO}_{2}$ surviennent pendant plus de $12 \mathrm{~h}$ après l'injection initiale, alors que dans le groupe fentanyl, ces effets ne sont présents que dans les premières heures de perfusion épidurale $(P<0,05)$. Dans le groupe morphine, les nausées sont plus sévères au cours des premières six heures $(P<0,01)$ et plus fréquentes (incidence de 53\% versus $28 \%$ sur une période de 24 heures, $P<0,05)$ que dans le groupe fentanyl. Les deux tiers des patients de chaque groupe présentent une somnolence importante plusieurs heures après le début du traitment. Le degré de somnolence diminue rapidement par la suite chez les patients du groupe morphine, alors que près de la moitie des patients du groupe fentanyl sont encore somnolents au deuxième jour de traitement. L'incidence de somnolence à 48 heures demeure plus élevées dans le groupe fentanyl $(P<0,05)$. Le prurit est plus sévère dans le groupe morphine $(P$ $<0,001)$ et augmente de façon quadratique dans le temps chez les patients de deux groupes $(P<0,001)$. Dans le groupe morphine, le prurit est généralisé alors qu'il est plutôt segmentaire dans le groupe fentanyl. Le prurit représente l'effet 
secondaire le plus important au deuxième jour dans les deux groupes. L'évolution des effets respiratoires et des nausées dans le temps est semblable à celle retrouvée après l'injection unique de ces narcotiques dans l'espace épidural. Les effets secondaires, à l'exception du prurit, sont moindres au deuxième jour dans les deux groupes, mais de façon générale, ils sont moins importants dans le groupe fentanyl. La perfusion épidurale continue de morphine ou de fentanyl est donc une technique sécuritaire d'analgésie prolongée et elle est associée à peu d'effets secondaires autres que ceux causés par l'injection initiale (bolus) de ces narcotiques dans l'espace épidural.

The side effects of epidural opioids are considered to be related to their rostral spread in the cerebrospinal fluid to supraspinal structures. ${ }^{1-3}$ The elimination half-life of morphine, a hydrophilic opioid, is approximately four hours in both cerebrospinal fluid and plasma compartments. ' However, the concentration attained in the cerebrospinal fluid following epidural injection is far in excess, in the second order, of that in plasma, and a high concentration of morphine is present even up to $24 \mathrm{hr}$ later.' Fentanyl, on the other hand, is very lipid soluble. Access of fentanyl to the spinal fluid is more rapid, but so is its uptake by the spinal veins, which results in less free drug in the CSF to migrate rostrally. Plasma concentrations of fentanyl have been shown to increase rapidly following epidural injection. ${ }^{4,5}$ Thus, the onset of analgesia is rapid, its duration is shorter, and the incidence of centrally mediated side effects may be reduced. ${ }^{6-9}$ During continuous epidural infusion, the rostral spread of these opioids is expected to be less than that following bolus injection since the cerebrospinal fluid concentrations in the vicinity of the site of infusion are expected to be lower. However, a comparative incidence has not been reported.

This study compared the side effects of epidural morphine and fentanyl. For this purpose, respiratory effects, nausea and vomiting, somnolence, and pruritus during continuous epidural infusion of morphine or fentanyl for postoperative pain relief were studied in 68 patients undergoing elective total replacement of the hip or knee joints.

\section{Methods}

Sixty-eight patients were studied. Institutionally approved informed consent was obtained from each patient. Patients with abnormal blood coagulation or bleeding time, patients with mental confusion, psychiatric diseases, and alcohol or drug abuse were excluded from the study. Patients were randomly assigned to either the morphine or fentanyl group.

Premedication was not given. Patients were sedated with midazolam, 1-2 $\mathrm{mg}$, as needed in the holding area. A lumbar epidural catheter was inserted at $\mathrm{L}_{2-3}$ or $\mathrm{L}_{3-4}$ interspace and was advanced $3 \mathrm{~cm}$ cephalad. A bolus of lidocaine $1.5 \%$ with epinephrine, 5 to $10 \mathrm{ml}$, was injected through the catheter. The catheter was considered to be in the epidural space when the patient felt a warm sensation and/or numbness in both lower extremities. Anaesthesia was induced with thiopentone 2 to $5 \mathrm{mg} \cdot \mathrm{kg}^{-1}$ and tracheal intubation was facilitated by succinylcholine. An indwelling catheter was inserted into the bladder. Anaesthesia was maintained with isoflurane and nitrous oxide, supplemented by fentanyl as needed.

Administration of bolus doses and initial adjustment of infusion rate were managed by one of the investigators in all study cases. Initial bolus doses of morphine, Duramorph ${ }^{\circledR}$ (Elkins-Sinn, Inc., Cherry Hill, NJ), were 1,000 to $4,000 \mu \mathrm{g}$ in a concentration of $1,000 \mu \mathrm{g} \cdot \mathrm{ml}^{-1}$, and initial infusion rates were 100 to $350 \mu \mathrm{g} \cdot \mathrm{hr}^{-1}$ in a concentration of $200 \mu \mathrm{g} \cdot \mathrm{ml}^{-1}$. Initial doses of fentanyl were 40 to $100 \mu \mathrm{g}$ in the concentration of $10 \mu \mathrm{g} \cdot \mathrm{ml}^{-1}$, and initial infusion rates were 20 to $80 \mu \mathrm{g} \cdot \mathrm{hr}^{-1}$ in the same concentration. The solution was prepared in preservativefree normal saline in a standard intravenous bag and was infused by a Life Care ${ }^{\circledR}$ pump-micro model (Abbott Laboratories, North Chicago, IL). Pain was assessed by a visual analogue scale (VAS) consisting of a $10-\mathrm{cm}$ line marked "no pain" at one end and "worst possible pain" at the other. ${ }^{10}$ The patient marked the line according to the pain perceived at the time of examination. The result was expressed as a unitless number ranging from 0 to 100 . A bolus injection was repeated as needed in increments of 1 to $2 \mathrm{ml}$, and the infusion rate was adjusted to obtain VAS pain scores of between 10 and 30 over a period of up to several hours. Patients were then instructed to call the evaluators whenever the pain or side effects were annoying. The infusion rate was adjusted by 0.5 to $1.0 \mathrm{ml} \cdot \mathrm{hr}^{-1}$ at a time for subsequent complaints of pain (VAS score $>30$ ). Evaluators and patients were blinded with respect to the identity of the opioid.

Respiratory effects were assessed by arterial blood gas analysis and respiratory rate. Nausea, " somnolence, ${ }^{11}$ and pruritus $^{12}$ were assessed by VAS. The worst nausea was defined to be present when there was retching or vomiting and the worst pruritus when it was unbearable to the point that patients preferred pain. The worst somnolence was defined to be present when patients could hardly keep their eyes open.

The first assessment of the variables was made at the time of the preoperative visit. The assessment was repeated $3,6,12,24,36$, and $48 \mathrm{hr}$ after the start of the epidural injection. The epidural infusion was discontinued at $48 \mathrm{hr}$, and the final assessment was made at $72 \mathrm{hr}$. Nausea was assessed at the time of complaint, since it tended to wane following vomiting or retching. The highest value was 
used as the score for the nearest time period. In the absence of complaints, VAS score for nausea was assessed at predetermined time periods.

The decision to treat side effects was made by the evaluators based on the assessment of degrees of pain and side effects. The infusion rate was changed in decrements of 0.5 to $1.0 \mathrm{ml} \cdot \mathrm{hr}^{-1}$ when the patient was pain-free or the pain was minimal. Patients with $\mathrm{PaCO}_{2}$ above $50 \mathrm{mmHg}$ and respiratory rate below $10 \mathrm{~min}^{-1}$ were observed closely. Further increase in $\mathrm{PaCO}_{2}$, together with further progression of somnolence and decline in respiratory rate, was defined to be an indication for naloxone treatment, and the patient was considered to be in respiratory failure. Respiratory failure and very severe pruritus were treated with intravenous infusion of naloxone 100 to $200 \mu \mathrm{g} \cdot \mathrm{hr}^{-1}$. Severe nausea was treated with metoclopramide 5 to 10 mg iv.

Differences between the groups and changes over time in VAS scores for pain and for each side effect were tested by analysis of variance for repeated measures design with the naloxone treatment as a time-varying covariate. The data were further tested where appropriate by Bonferroni simultaneous confidence intervals for differences and changes. Side effects were arbitrarily considered to be present when the VAS score was above 30 . Incidences of side effects thus defined were tested by Koch's method for the analysis of categorical data for repeated measurement. ${ }^{13}$ Since there were only 68 patients in the study, analysis was performed between two time periods. The 72 hr VAS scores were tested by the unpaired Student's test. The cumulative incidence of patients who developed side effects was tested by Chi-square test for each side effect at all time periods. All incidences at $72 \mathrm{hr}$ were tested by Chi-square test.

\section{Results}

The epidural space could not be located in two of the 68 patients. Of the remaining 66,34 ( 14 men and 20 women) received epidural morphine and 32 (16 men and 16 women) received epidural fentanyl. There were no differences in age, height, or weight between the groups (Table). The mean bolus dose and epidural infusion rate were 3,900 $\pm 1,300 \mu \mathrm{g}$ (range, $1,000-6,000 \mu \mathrm{g}$ ) and $427 \pm 213$ $\mu \mathrm{g} \cdot \mathrm{hr}^{-1}$ (range, $100-800 \mu \mathrm{g} \cdot \mathrm{hr}^{-1}$ ) for morphine and $85 \pm$ $46 \mu \mathrm{g}$ (range $40-230 \mu \mathrm{g}$ ) and $56 \pm 27 \mu \mathrm{g} \cdot \mathrm{hr}^{-1}$ (range $20-120 \mu \mathrm{g} \cdot \mathrm{hr}^{-1}$ ) for fentanyl, respectively. The bolus doses and infusion rates were inversely related to age (bolus dose, $\mathrm{R}=-0.63, P<0.001$ for morphine and $\mathrm{R}=$ $-0.54, P<0.01$ for fentanyl; and infusion rate, $R=$ $-0.37, P<0.05$ for morphine and $\mathrm{R}=-0.47, P<0.01$ for fentanyl). Twenty-eight of these patients had a history of hypertension, eight had coronary heart disease, 12 had chronic obstructive lung disease, nine had diabetes
TABLE Demographic data (mean \pm SD with range in parentheses)

\begin{tabular}{lll}
\hline & Morphine $(n=34)$ & Fentanyl $(n=32)$ \\
\hline Age $(\mathrm{yr})$ & $56 \pm 18$ & $59 \pm 14$ \\
& $(19-79)$ & $(29-86)$ \\
Height $(\mathrm{cm})$ & $170 \pm 11$ & $170 \pm 9$ \\
& $(155-191)$ & $(155-188)$ \\
Weight $(\mathrm{kg})$ & $81.4 \pm 17.1$ & $80.6 \pm 17.0$ \\
& $(50-117)$ & $(55-132)$ \\
Hip replacement & 18 & 16 \\
Knee replacement & 16 & 16 \\
\hline
\end{tabular}

mellitus, and three had a history of cerebrovascular accidents. Thirty-five patients had total replacement of the hip joint and 31 had unilateral or bilateral total replacement of the knee joint. There was no difference in the intraoperative fentanyl dose between the groups (morphine group $245 \pm 95 \mu \mathrm{g}$ and fentanyl group $255 \pm 105 \mu \mathrm{g}$ ).

Four patients in the morphine group were treated with continuous intravenous infusion of naloxone to combat respiratory depression in two and severe generalized pruritus in the other two. Naloxone treatment was a covariate in the analysis of VAS scores for pruritus $(P<$ 0.02 ) but not for pain, nausea, somnolence, or respiratory variables.

Pain relief was similar in both groups (Figure 1). There was no group-time interaction, group effect, or time effect in the scores. All except two patients who were treated with naloxone infusion for pruritus rated the epidural method as satisfactory.

There was a group-time interaction for $\mathrm{PaCO}_{2}(P<$ $0.001)$ and a time effect for respiratory frequency $(P<$ 0.001 ). The $\mathrm{PaCO}_{2}$ increased in the morphine group and the values for the $3 \mathrm{rd}, 6 \mathrm{th}$, and $12 \mathrm{th} \mathrm{hr}$ were higher than the preoperative values $(P<0.02)$, but $\mathrm{PaCO}_{2}$ did not change in the fentanyl group (Figure 2). The decrease in respiratory frequency was significant only at three hours in both groups $(P<0.025)$. Respiratory depression developed in two patients in the morphine group. Hypercarbia $\left(\mathrm{PaCO}_{2}, 59 \mathrm{mmHg}\right)$ associated with drowsiness at three hours in one of these patients was treated with a continuous infusion of naloxone. Hypercarbia in the other patient progressed from $51 \mathrm{mmHg}$ at three hours to $60 \mathrm{mmHg}$, together with the development of marked drowsiness despite naloxone infusion, $100 \mu \mathrm{g} \cdot \mathrm{hr}^{-1}$. This patient responded to the increase in the infusion rate to 200 $\mu \mathrm{g} \cdot \mathrm{hr}^{-1}$. The naloxone infusion was terminated in both patients the following morning.

There were group-time interactions in the nausea scores $(P<0.05)$. Nausea developed over the period of $12 \mathrm{hr}$ in the morphine group, but nausea in the fentanyl group had occurred mostly by three hours (Figure 3). Subsequently, the score and incidence decreased and remained at values 

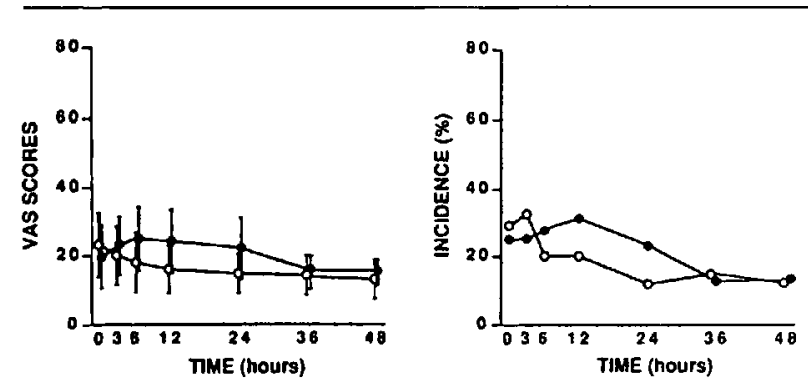

FIGURE 1 The mean visual analogue scale (VAS) score for pain with 95 per cent confidence intervals and the incidence of patients with insufficient pain relief (VAS > 30). 0 ... 0 morphine, -.-- fentanyl.

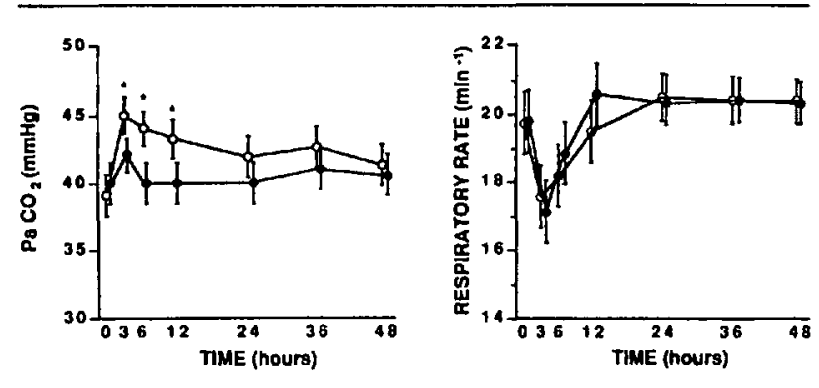

FIGURE 2 The mean $\mathrm{PaCO}_{2}(\mathrm{mmHg})$ and respiratory rate $\left(\mathrm{m}^{-1}\right)$ with 95 per cent confidence intervals. ${ }^{*} P<0.01$ compared between the

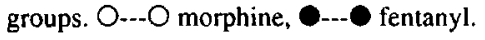

no different from the preoperative levels. The score and incidence were both higher in the morphine group at six hours. The cumulative incidence at the 12th and 24th hr was higher in the morphine group ( $53 \%$ vs $28 \%, P<0.05$, respectively) (Figure 4). Eleven of 16 in the morphine group and three of nine in the fentanyl group were treated with metoclopramide.

There was a time effect in the somnolence scores $(P<$ $0.001)$. There was also a group-time interaction in the analysis of the $24-48 \mathrm{hr}$ incidence $(P<0.01)$. Somnolence was equally prominent in both groups within several hours. By $24 \mathrm{hr}$, it was moderate and most patients were readily communicable (Figure 3 ). Somnolence continued to improve further in the morphine group, but it remained unchanged at $24 \mathrm{hr}$ level in the fentanyl group. Somnolence was less in the morphine group at $48 \mathrm{hr}(P<0.05)$.

There were group as well as time effects in the pruritus scores $(P<0.001)$. There was a quadratic increase in the scores, and pruritus was the only major subjective complaint during the second day. The score and incidence were higher in the morphine group (Figures 3 and 4). Two patients in the morphine group required naloxone infusion for treatment. Six patients continued to have pruritus $24 \mathrm{hr}$ after cessation of epidural morphine. There were also

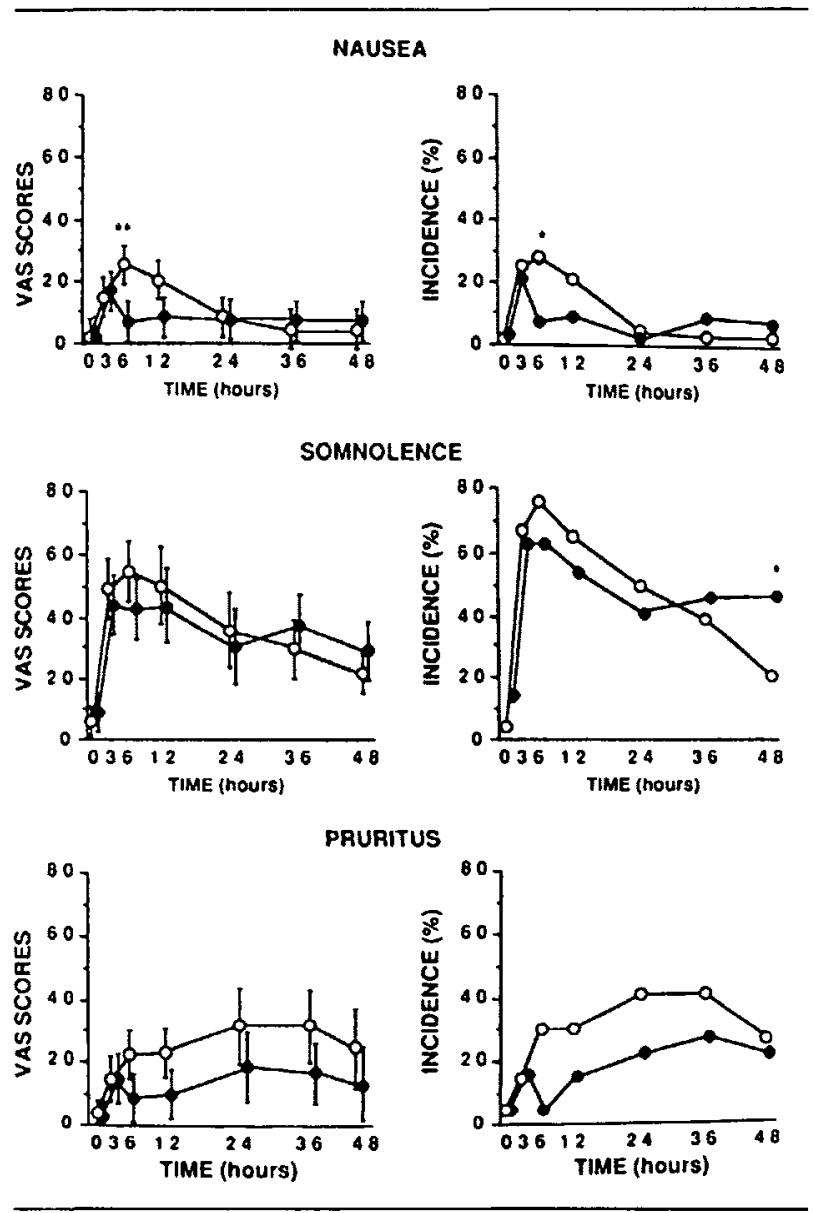

FIGURE 3 The mean visual analogue scale (VAS) scores with 95 per cent confidence intervals and the incidences (VAS $>30$ ) for nausea, somnolence and pruritus. ${ }^{*} P<0.05$ and ${ }^{* *} P<0.01$ compared between the groups. $O---O$ morphine, ---- fentanyl.

group-time interactions in analyses of the preoperative, three and six hour incidences $(P<0.01)$. The initial increase in the incidence at three hours in the fentanyl group $(P<0.01)$ was followed by a decline to the preoperative level at six hours. The incidence then gradually increased during the continuous infusion.

The location of pruritus was recorded in 19 out of 21 patients in the morphine group and 10 out of 17 patients in the fentanyl group. In the morphine group, 15 patients noted it first in the face or nose, which became generalized in 13. In the remaining four patients, it was patchy, sparing the face, and was usually localized to the upper arms, chest, or trunk. In addition, mild pruritus in the tape site on the back occurred frequently. In the fentanyl group, pruritus was segmental in seven of ten patients and spared the face. Five in the morphine group and four in the fentanyl group noted either absence of pruritus or, if present, markedly less intense pruritus in the extremities on which operations had been performed. One patient 

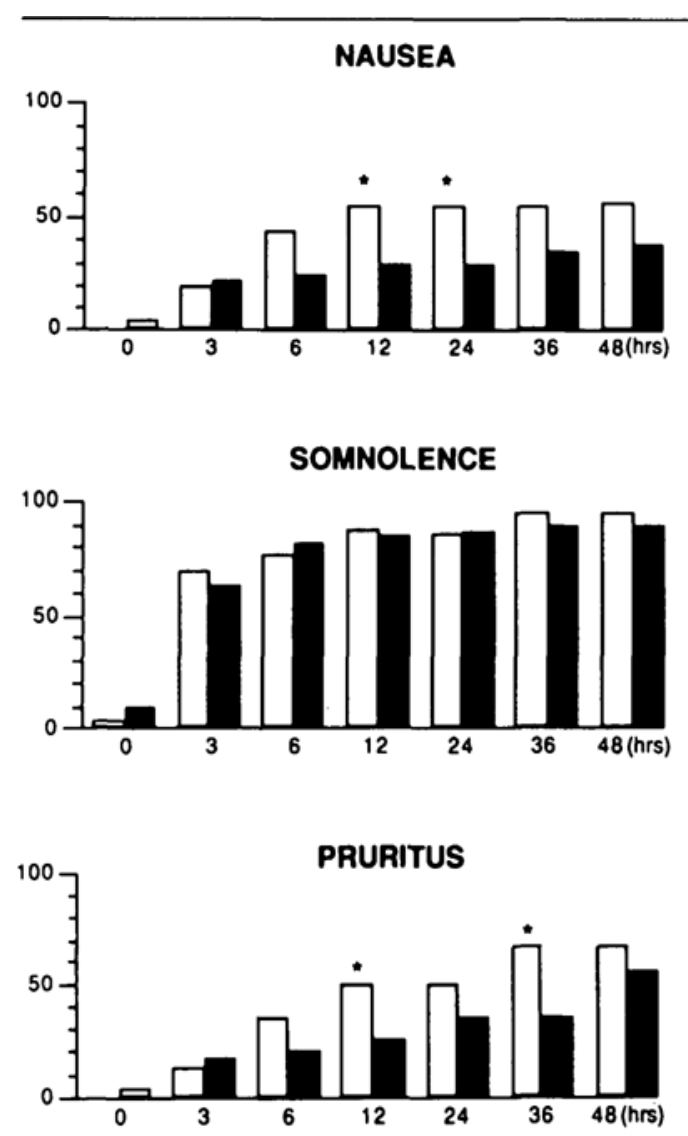

FIGURE 4 Cumulative incidences (per cent) of patients who developed nausea, somnolence and pruritus. ${ }^{*} P<0.05$. $\square$ morphine, fentanyl.

developed an extreme hypersensitivity to touch in both lower extremities that elicited agonizing pain.

A brief visual hallucination was observed in one patient several hours after epidural morphine. Hypotension developed in an 86-yr-old woman following three boluses (total $40 \mu \mathrm{g}$ ) of epidural fentanyl. The patient required dopamine infusion at the rate of $5 \mu \mathrm{g} \cdot \mathrm{kg}^{-1} \cdot \mathrm{min}^{-1}$ for maintenance of blood pressure for approximately four hours. Bowel sounds were detectable by the second day of infusion in all but one patient in the fentanyl group.

Most patients ambulated on the second postoperative day. The duration of postoperative hospitalization was $7.4 \pm 1.3$ days (range, $5-12$ days). Minor postoperative complications developed in seven patients: urinary tract infection in three, pulmonary atelectasis in one, deep vein phlebitis in one, ileus in one, and wound erythema in one. All the complications resolved without further treatment.

\section{Discussion}

In this study, both morphine and fentanyl provided adequate and steady postoperative pain relief during a 48 hr period of continuous epidural infusion; pain relief was similar in both groups. However, the severity and pattern of side effects differed between groups as well as among the side effects. Respiratory effects and nausea could be observed for more than $12 \mathrm{hr}$ in the morphine group, whereas changes were less severe and confined to the first few hours in the fentanyl group. Somnolence was an equally prominent side effect in both groups within several hours. By $24 \mathrm{hr}$, somnolence was less in both groups and was not of clinical significance. However, while it remained at this level in the fentanyl group, it decreased further in the morphine group. Pruritus continued to increase into the second 24-hr period. It was more severe and tended to be generalized in the morphine group but was segmental in the fentanyl group.

The cerebrospinal fluid pharmacokinetic behaviour of morphine predicts that the effects of epidural morphine on the brainstem should be demonstrable as late as $24 \mathrm{hr}$ after a bolus injection. ${ }^{1,14-16}$ The pharmacokinetics of epidural fentanyl in the cerebrospinal fluid suggests that rostral spread of fentanyl may occur after lumbar injection, but that concentrations high enough to produce clinical effects may not be sustained at the brainstem level. ${ }^{17}$ Epidural fentanyl, though shown to decrease ventilatory response to carbon dioxide, is not associated with $\mathrm{PaCO}_{2}$ elevation. ${ }^{22,23}$ During continuous epidural infusion, plasma fentanyl concentrations have been shown to reach the levels above the lower limit of the threshold concentration, but alveolar ventilation is usually not affected, $, 19,20$ unless larger doses were used. ${ }^{21}$ These reports suggest also that significant rostral migration of fentanyl had not occurred following a bolus injection and during the continuous infusion into the epidural space. The patterns of respiratory effects and nausea observed in our patients were similar to those that follow a bolus epidural injection of morphine and fentanyl, respectively. The differences in severity, incidence, and temporal course between the groups were consistent with those expected from differences in the cerebrospinal fluid pharmacokinetics of the respective opioids. The subsequent incidence of the side effects was minimal in both groups, suggesting that brainstem concentrations high enough to cause respiratory depression or nausea were not attained during the continuous infusion of either fentanyl or morphine.

Somnolence has been described following epidural injection of morphine ${ }^{22,23}$ as well as fentanyl. ${ }^{8,24}$ In this study, somnolence was the most frequent side effect among those studied, occurring in approximately two thirds of patients in both groups within several hours of treatment. The temporal course of somnolence in the morphine group, i.e., subsequent continued improvement, appears to be consistent with that expected from the pharmacokinetic behavior of an initial bolus dose of morphine in the cerebrospinal fluid. On the other hand, 
approximately half of the patients in the fentanyl group continued to have somnolence during the entire second 24$\mathrm{hr}$ period. The electroencephalographic pattern that follows intravenous fentanyl $2 \mu \mathrm{g} \cdot \mathrm{kg}^{-1}$ is comparable to the state of reduced mental vigilance in man, just below the state of light sleep for up to $90 \mathrm{~min} .{ }^{25}$ In 1985 , Ahuja and Strunin reported that plasma fentanyl concentrations during the continuous epidural infusion were $0.4 \mathrm{ng} \cdot \mathrm{ml}^{-1}$ at $6 \mathrm{hr}$ and $0.6 \mathrm{ng} \cdot \mathrm{ml}^{-1}$ at $18 \mathrm{hr}$ with an infusion rate of 1 $\mu \mathrm{g} \cdot \mathrm{kg}^{-1} \cdot \mathrm{hr} .{ }^{20}$ Renaud et al. reported the values of 1 $\mathrm{ng} \cdot \mathrm{ml}^{-1}$ and $1.5 \mathrm{ng} \cdot \mathrm{ml}^{-1}$ at similar time periods. ${ }^{19}$ Plasma concentrations that build up during continuous infusion may account for the slow decline in the measures of somnolence and its persistence during the second day in the fentanyl group.

The mechanism of epidural opioid-induced pruritus is not known. Ballantine et al. advanced an hypothesis that pruritus may be a manifestation of opioid-mediated facilitation of protective reflexes. ${ }^{26}$ Opioids suppress noxiously induced reflexes but also excite neurons that do not receive a nociceptive impulse. ${ }^{27}$ Following an initial reflex withdrawal, protective reflexes result in hyperalgesia or pruritus in the vicinity of the injury. This hyperalgesia is an antipruritic state, and such attenuation is clearly shown to be mediated at the spinal cord level. ${ }^{28,29}$ In our patients, pruritus persisted in the second 24 -hr period while pain relief was adequate and other side effects were declining or had declined. Pruritus was absent in the extremity on which operation was performed and the distribution of pruritus was clearly segmental in the fentanyl group, suggesting that events occurring at the spinal cord are also important in the pathogenesis of pruritus.

Since the majority of our patients were elderly and sedentary, we were cautious with the doses of opioids. However, two elderly patients developed respiratory failure requiring naloxone treatment. In this study, fixed doses were not used. Although the bolus and infusion doses needed to obtain pain relief were inversely related to age in both groups, there was a wide scatter around the regression lines. Fixed doses, even if age-adjusted, would have resulted in a substantial number of patients with inadequate pain relief or marked side effects. In addition, the investigator managing the initial boluses and infusion of narcotics was not blinded and, since equivolumetric doses of morphine and fentanyl were not used, evaluators may not have been blinded during subsequent observations. This could have produced a potential bias in the results. The effects of residual anaesthesia also may have influenced side effects in the early stage of epidural opioids. Thus, the true incidence as well as intensity of early side effects may be different from those observed in this study.
However, the temporal course of respiratory effects and nausea in our patients was similar to that which occurred in volunteers following a bolus injection. ${ }^{14,18}$ Hypotension that developed in one patient occurred in the immediate postoperative period. Bowel sounds had returned by the second day in all but one patient. During the second day of continuous infusion, the only side effect of clinical concern was pruritus, notably in the morphine group. The side effects were generally less in the fentanyl group with the exception of moderate somnolence that persisted on the second day of infusion. The continuous epidural infusion of opioids, after the initial bolus-related side effects, appears to be a safe technique to provide prolonged and steady pain relief with minimal side effects.

\section{References}

1 Nordberg G, Hedner T, Mellstrand T, Dahlstroem B. Pharmacokinetic aspects of epidural morphine analgesia. Anesthesiology 1983; 58: 545-51.

2 Max MB, Inturrisi CE, Kaiko RF Grabinski PY, Li CH, Foley $K M$. Epidural and plasma profile in patients with chronic cancer pain. Clin Pharmacol Ther 1985; 38: 631-41.

3 Gourlay GK, Cherry DA, Cousins MJ. Cephalad migration of morphine in CSF, following lumbar epidural administration in patients with cancer pain. Pain 1985; 23: 317-26.

4 Justins DM, Francis D, Houlton PG, Reynolds F. Epidural versus intramuscular fentanyl: analgesia and pharmacokinetics in labor. Anaesthesia 1983; 38: 937-42.

5 Lomessy A, Magnin C, Viale JP, Motin J, Cohen R. Clinical advantages of fentanyl given epidurally for postoperative analgesia. Anesthesiology 1984; 61: 466-9.

6 Brownridge $P$. Epidural and intrathecal opiates for postoperative pain relief. Anaesthesia 1983; 38: 74-5.

7 Mackersie RC, Shackford SR, Hoyt DB, Karagianes TG. Continuous epidural fentanyl analgesia: ventilatory function improvement with routine use in treatment of blunt chest injury. J Trauma 1987; 27: 1207-12.

8 Cough JD, Williams AB, Vaughan RS, Khalil JF, Butchart $E G$. The control of post-thoracotomy pain. A comparative evaluation of thoracic epidural fentanyl infusions and cryo-analgesia. Anaesthesia 1988; 43: 780-3.

9 Kreitzer $J M$, Kirschenbaum LP, Eisenkraft $J B$. Epidural fentanyl by continuous infusion for relief of postoperative pain. Clin J Pain 1989; 5: 283-90.

10 Price DD, McGroth PA, Raffie A, Puckingham B. The validation of visual analog scales as ratio score measures for chronic and experimental pain. Pain 1983; 17: 45-56.

11 Welchew EA. The optimum concentration for epidural fentanyl. Anaesthesia 1983; 38: 1037-41.

12 Douglas MJ, Kim JHK, Ross PLE, McMorland GH. The effect of epinephrine in local anaesthetic on epidural 
morphine-induced pruritus. Can Anaesth Soc J 1986; 33: $737-40$.

13 Koch GG, Landis JR, Freeman JI, Freeman DH, Lehnen $R G$. A generalized methodology for the analysis of experiments with repeated measurement of categorical data. Biometrics 1977; 33: 133-52.

14 Bromage PR, Camporesi EM, Durant PAC, Nielsen CH. Rostral spread of epidural morphine. Anesthesiology 1982; 56: 431-6.

15 Knil RL, Clement JL, Thompson WR. Epidural morphine causes delayed and prolonged ventilatory depression. Can Anaesth Soc J 1981; 28: 537-43.

16 Camporesi EN, Nielsen CH, Bromage PR, Durant PAC. Ventilatory $\mathrm{CO}_{2}$ sensitivity after intravenous and epidural morphine in volunteers. Anesth Analg 1983; 62: 633-40.

17 Gourlay GK, Murphy TM, Plummer JL, Kowalski SR, Cherry DA, Cousins MJ. Pharmacokinetics of fentanyl in lumbar and cervical CSF following lumbar epidural and intravenous administration. Pain 1989; 38: 253-9.

18 Negre I, Queneron JP, Ecoffey C, et al. Ventilatory response to carbon dioxide after intramuscular and epidural fentanyl. Anesth Analg 1987; 66: 707-10.

19 Renaud B, Brichant JF, Clergne F, Chauvin M, Levron $J C$, Viars $P$. Ventilatory effects of continuous epidural infusion of fentanyl. Anesth Analg 1988; 67: 971-5.

20 Ahuja BR, Strunin $L$. Respiratory effects of epidural fentanyl. Anaesthesia 1985; 40: 949-55.

21 Badner NH, Sandler AN, Koren G, Lawson SL, Klein J, Einarson $T R$. Lumbar epidural fentanyl infusions for post-thoracotomy patients: analgesia, respiratory, and pharmacokinetic effects. Journal of Cardiothoracic Anesthesia 1990; 4: 543-51.

22 Baxter AD, Samson B, Penning J, Doran R, Dube LM. Prevention of epidural morphine-induced respiratory depression with intravenous nalbuphine infusion in postthoracotomy patients. Can J Anaesth 1989; 36: 503-9.

23 Naji $P$, Farschtschian $M$, Wilder-Smith $O H$, Wilder-Smith $\mathrm{CH}$. Epidural droperidol and morphine for postoperative pain. Anesth Analg 1990; 70: 583-8.

24 Weichow EA, Thornton JA. Continuous thoracic epidural fentanyl. Anaesthesia 1982; 37: 309-16.

25 Kugler J, Grote B, Laub M, Doenicke A, Dick E. Die hypnotische Wirkung von Fentanyl und Sufentanil. Anaesthesist 1977; 26: 343-8.

26 Ballantine JC, Loach $A B$, Carr $D B$. Itching after epidural and spinal opiates. Pain 1988; 33: 149-60.

27 Belcher G, Ryall PW. Differential excitatory and inhibitory effects of opiates on nonnociceptive and nociceptive neurons in the spinal cord of the cat. Brain Pes 1978; 145 ; 303-14.
28 Bickford RG. Experiments relating to the itch sensation: its peripheral mechanism, and central pathways. Clin Sci 1938; 3: 377-86.

29 Graham DT, Goodell H, Wolf HG. Neural mechanisms involved in itch, "itchy skin" and tickle sensations. J Clin Invest 1951; 30: 37-49. 